\title{
METHODOLOGICAL IMPROVEMENTS IN THE FINAL PROJECT OF CIVIL ENGINEERING DEGREE
}

\author{
F. Contreras de Villar ${ }^{1}$, J.J. Muñoz Pérez ${ }^{1}$, A. Contreras de Villar ${ }^{1}$, O. Castillo \\ López ${ }^{1}$, A. Torregrosa Martínez ${ }^{1}$, A.L. Duarte Sastre ${ }^{1}$, F.J. Manzano Diosdado', \\ A. Gil Ropero', J.M. Triano Rodríguez², M. Díaz Gómez ${ }^{3}$, F. Ruiz ${ }^{3}$ \\ ${ }^{1}$ Cadiz University (SPAIN) \\ ${ }^{2}$ Ayuntamiento de Algeciras (SPAIN) \\ ${ }^{3}$ Autoridad Portuaria Bahia Algeciras (SPAIN)
}

\begin{abstract}
The final project of an engineering degree represents a test of maturity where students must crossexamine all the contents studied in the degree which adds technical difficulties. Traditionally the students are supervised by only one teacher and they usually also take a previous course in the writing of the project. Currently, the program of the Civil Engineering Degree contemplates this activity in the last semester with an allocation of 18 credits. The hardest difficulty noted by students and teachers is the short time estimated for writing it. A teaching innovation project is presented herein which aims to define a working protocol in order to help the student in a more efficient and close way during the development of the task. Among the methodological changes introduced, it should be highlighted the tutoring by professors from different areas of knowledge instead of only one professor as it was traditionally done. Thus, coordination mechanisms must be implemented to guarantee the achievement of the proposed objectives. The innovation project also helps to identify tasks that can be advanced in time and gain time for the effective drafting of the project. Some other solutions found will be presented as well as a comparison of the results obtained along this year with those of the former methodology.
\end{abstract}

Keywords: Innovation, technology, Civil, Engineering, Degree, Project.

\section{INTRODUCTION}

The report of the Degree in Civil Engineering that is studied at the Higher Polytechnic School of Algeciras establishes the organization of official university education in accordance with Order CIN307 / 2009 of February 9 which in turn responds to Annex I of Royal Decree 1393 / 2007, of October 29, in which section 3 defines a module expressly dedicated to the realization of an End-of-Degree Project as another subject to which 18 credits have been assigned. It is also a requirement that it be carried out at the end of the period of studies and that is oriented to the evaluation of the competences of the degree [1]. However, and despite this "legislative" comparison with other subjects ([2], [3], [4]) the PFG ((Final project of the degree, Proyecto Fin de Grado in Spanish) is considered a tough test by university students, due to several regulatory and academic factors.

To begin with, most universities include restrictive requirements to allow their defense. Among the most important (for frequent ones), we highlight the requirement of having passed all or almost all the ECTS that make up the degree. On the other hand, the PFG forces students to demonstrate that they have acquired, on the one hand, the knowledge of their profession (Civil Engineer) and, on the other hand, the skills that the degree has defined for their graduates. In addition, the defense of the PFG is an oral and public act before the court. This is another factor that adds to the difficulty of the PFG, because oral tests are generally not the preferred evaluation modality among university professors ([5]) and, therefore, students are not usually accustomed. to them. That means that there are innate abilities (such as public speaking), in addition to those acquired in the development of the university degree (argumentation, presentation and preparation of the presentation, among others), which students must use during the public act of defense of the PFG and that, normally, has not had time (or opportunity) to rehearse enough with his tutor.

Finally, the act of assigning tutors [6] to university students is often a complex process for both actors, since the assignment is sometimes done randomly from the Department in charge of teaching or from the commission that oversees the award of projects. We understand that this procedure is improvable, since it is carried out ignoring the personal traits of university students and teachers, who are put to 
work together in an academic process that, in advance, requires a good dose of empathy for both parties ([7], [8], [9]).

It is, therefore, an area that poses academic, personal and pedagogical challenges to students, in addition to overcoming a bureaucracy that, in most cases, is not comparable with what implies any other subject of its University degree.

The PFGs constitute, therefore, one of the most outstanding novelties of the Spanish university system, which has had to address, in most cases, from the lack of knowledge about how they would work and develop ([10], [11]), what would be its impact at the academic, institutional and professional level, as well as in what way they would be welcomed by the students.

We will address in this article the description of a teaching innovation project that has been carried out during the 2018-2019 academic year and that continues during the 2019-2020 academic year. This project has grouped 12 students of the Degree in Civil Engineering in the specialties of Civil Construction, Hydrology and Transportation.

Group sessions were designed ([12], [13]) carrying out a planned tutorial action work with which the participating students felt accompanied, guided and encouraged at all times. This process culminated with a series of individualized tutorials (in which the final correction of the PFGs prior to their deposit was treated), to which was added, as a final phase, the exhibition essay (again in group) of the defense of their PFG (phase in which they were also accompanied by the teachers participating in this group and who previously advised them on the formats of the presentations, the speech they had to prepare, the questions to which they could be exposed or the university protocol that they had to drive in an academic act).

We will analyze data from a qualitative analysis from the interviews conducted to the participating students. This article will present its analysis and conclusions in the light of the approach and the results of the project, but not before sketching a series of proposals for improvement essential to facilitate our graduates who compete equally with renowned international university systems that emphasize in that quality.

The aim of this paper is to present a new methodology that facilitates the realization of the PFG to both students and teachers

\section{METHODOLOGY}

The work proposal supposes an important methodological change such as tutoring by teachers from different areas of knowledge instead of a teacher as traditionally. This fact will force the implementation of coordination mechanisms to guarantee the achievement of the objectives set.

The Project Classroom is created to fulfill the objectives of the project. This concept includes a physical space (classroom) equipped with computer equipment with the necessary software for the development of projects.

The project also seeks to identify tasks that can be advanced in time and thus save time for the effective drafting of the project.

The protocol previously carried out proposed that the project be defined by the tutor or the student whenever it was an original work, this required that the student had to go to the appropriate institutions to require the initial documentation. This fact generated inconvenience in the institutions since the request for information was not channelled and there were many students who visited the institutions at the same time that the acquisition of the starting documentation was delayed.

The project seeks to detect needs in local and regional institutions (Town Halls, Commonwealth, Port Authority) so as to be able to offer students real projects and with easy access to starting information, this will generate synergies between the Polytechnic School and said organisms and not losing sight of what these advances mean to the student.

The general purpose of this innovation project is to contribute to the design and development of the Final Degree Project by launching collaborative learning as a didactic and evaluation strategy.

More specifically, we can specify this general purpose in the following specific objectives:

- Apply learning strategies that favor student motivation.

- Contribute to the development of teamwork. 
- Improve student learning outcomes.

- Promote debate and reflection.

- Promote learning methodologies that actively promote research.

- Develop and effectively implement processes of accompaniment, guidance and advice for students.

- Design and elaborate the Final Degree Projects.

Collaborative Learning (CL) can be considered a model in which a group of students, more or less reduced, with different levels and skills, share a specific task and everyone is responsible not only for their own learning, but also for their companions. In this way they make up the search for common ends and share their achievement [14]. One of the fundamental characteristics of the AC is its flexibility, since it implies a teaching method that can be used in response to the diversity of interests, subjects, student needs, etc.,

Group meetings will favor interaction between students and teachers where questions, solutions and experiences between the group can be raised and exchanged. This process can be very useful for students, by contrasting and verifying that the problems that arise are very common and common in this type of work. But, above all, and more importantly, students are not alone or isolated to solve them.

In addition, individual tutoring is developed, in which each student and their tutor carry out more personalized attention and, in an exchange of information, knowledge and experiences, they are building, solving and addressing the performance of their work. In this type of tutoring, which can be carried out in person or online, the tutor exercises two very important functions in the PFG tutoring process: advises students in a personalized way, on the one hand, on their subject and, on the other, on the organization and planning of group work. This entire tutoring process will culminate in a work carried out with a dynamic of accompaniment, not only by the tutor, but also by the other classmates, also called equals. This type of method derived from cooperative learning comes from the Anglo-Saxon field (peer tutoring) and is defined by [15] as the development of skills and abilities thanks to the help and interaction of couples or partners.

The applied methodology requires the following phases of execution:

\subsection{Meetings at the beginning}

\subsubsection{Initial Meeting with institutions and / or companies with collaboration agreement}

The Coordinator of the Project Classroom (CPC) will meet with the institutions and companies that have formalized the mandatory collaboration agreements and in this way gather real technical needs that can be translated into the drafting of Final Degree Projects. In this Project the institutions that have collaborated are:

- City Council Algeciras.

- City Council La Línea de la Concepción.

- City Council Los Barrios.

- Port Bahía de Algeciras.

- Sergeyco Andalucía S.L.

The projects that are of interest will be related to each of the participating institutions. Promoting this coordination will generate synergies between the two institutions (University-Company) and all this will have an impact on the quality of the projects to be written and the integration of the University into the business fabric of the region.

\subsubsection{Initial group meeting}

When the student faces the writing of the Final Degree Project is in the last semester and given the difficulty of the technical careers, they mostly reach this point with more than two subjects, which is what the recommended curriculum itinerary indicates. It is very important to inform the students of the requirements that the project will entail. 
In this meeting, all students interested in starting to develop their Project will be convened. Students with different academic and / or personal profiles will attend, a very important fact to identify difficulties and set reasonable goals. They are distinguished:

- Students with a lot of teaching load.

- Students who combine their teaching activity with professional activity.

- Displaced students.

- Students with the teaching load exceeded or with a minimum pending teaching load.

\subsubsection{Initial Individual meeting}

The CPC will meet with each student personally and collect information on:

- Academic situation (pending subjects, curricular specialization)

- Availability of time for both the presence in the classroom and individual work

- Preferences for choosing the theme of the Project to be developed.

\subsection{Project assignment}

Once the projects required by the institutions and / or companies have been obtained and the curricular itineraries of the students analyzed, a meeting will be held where these projects will be exposed to the students and assigned according to the following criteria:

- In case of agreement between the students, each of them will choose the one that best suits their profile.

- In the case that two students want to carry out the same Project, preference will be given to the student with the best academic record.

\subsection{Sessions programming}

The program is included in the second semester of the fourth year and consists of a duration of 7 months, including the June and September calls. The following types of sessions are distinguished:

\subsubsection{Coordination meeting with the CPC}

One day of the week will be defined so that the CPC maintains a face-to-face group tutoring and detects the needs that both the group and the students need. This meeting can also be held virtually for students who are displaced outside the town.

\subsubsection{Face-to-face sessions of Teachers members of the Classroom}

This Project includes professors from all areas of knowledge who teach in the Civil Engineering Degree, in this way, in addition to the transversal professional experience that each teacher can contribute, specialization is added in the areas of knowledge in which they teach.

The students' first month of work consists in analyzing the chosen proposal, proposing alternatives and deciding which one is the most suitable. In this first month each teacher will intervene every week so that students receive ideas and proposals from all of them promoting critical reasoning and favoring decision making.

At the end of the first month, the CAP will convene weekly to the different teachers according to the needs of the students, typical of the progress of the projects.

\subsection{Supervision}

One of the objectives of the innovation proposal is the continuous monitoring and evaluation of the PFG for this purpose the following control mechanisms have been defined

\subsubsection{Initial evaluation of the proposal}

After one month of the assignment of the projects, students must complete the Project request with their proposal and defend it orally before the classroom teachers. In this evaluation the students will begin to 
work in the oratory, exposition and defense of the ideas. Teachers through suggestions and questions will help students to mature the proposed proposals.

\subsubsection{Midterm evaluations}

As the drafting of the projects progresses, the students will upload the provisional documents to the virtual campus so that the teaching staff can include comments and / or revisions they deem. It must be understood that the drafting of a Civil Engineering Project is dynamic and that as the development of the project progresses, incidents that involve the revision of previously drafted documents may appear. In any case, both face-to-face meetings as well as these intermediate reviews allow students to be continuously monitored.

\subsubsection{Final evaluation}

After the intermediate evaluations, the students will upload the complete document to the virtual platform where the participating faculty will review the PFG and will propose in the case that it considers corrections. In the case of having required corrections, the student will be allowed to incorporate the requested corrections and in this way increase the quality of the written PFGs.

The Campus Secretariat, once it has been verified that the student meets the requirements established for the defense, will send all the documentation to the President of the End of Degree Projects Committee (EDPC), who will be responsible for transferring it to the Evaluation Commission appointed by the EDPC .

The place, day and time of the defense will be fixed in each call, being made public at least fifteen calendar days before the event is held.

It will be a necessary condition for the defense of the PFG that the Evaluation Committee has the CAP report at its disposal, detailing the degree of compliance according to the objectives set

When the PFG is carried out in another institution (company, exchange agreement, etc.), both the CAP and the external co-author must submit an individual report.

The exhibition will be oral and public defense of the PFG, each student will have a minimum time of 15 minutes and a maximum of 30 minutes.

After the presentation, the members of the Commission may formulate the clarifications or questions they deem appropriate in order to evaluate the different aspects reflected in the work.

The evaluation commission will deliberate behind closed doors on the qualification of the projects submitted for evaluation. The overall qualification will take into account, at least, the scientific and technical quality of the project presented, the characteristics of the material delivered, the clarity of exposition, the capacity for debate and plot defense and the report of the tutor. The final grade will be the weighted arithmetic average of the marks attributed to the project by the members of the evaluation commission. The student who has not passed the evaluation or defense phase of his project, will obtain the qualification of suspense, having to attend another call through the procedure established in the center. Finally, the minutes will be completed and will be signed for this purpose and signed by all the members of the Evaluation Committee of the Final Degree Project.

\section{RESULTS}

Personal interviews were conducted with each of the students and teachers. The observation by the ten professors who have intervened in the process has allowed the analysis of the observed evidence. One of the greatest difficulties highlighted and collected during the process was the concretion and structuring of the content and the search for relevant information. Among other notes collected by teachers, we find the positive result of the different and continuous social interactions that occurred in the different groups, which contributed to improving the climate of coexistence and collaboration among students.

Among the ideas that students pointed out in relation to the innovation of the project, they established the following ideas:

- Initial ignorance

- Insecurity when starting the process.

- Doubts regarding the type of PFG that best suited your interests. 
- Difficulties

- The PFG takes a lot of time and dedication.

- Difficulty structuring content.

- Problems to set specific objectives.

- Expectations

- There is a high motivation to make a good PFG.

- Positive assessment of group learning.

In general, the result of the opinions showed that there are many difficulties at the beginning of the process, but, usually, there is a satisfactory assessment of the dynamics followed, especially highlighting the motivating character of facing a new task together, which mitigates the moments of insecurity and initial confusion. On the other hand, following the set of questions we ask students to reflect on the possible advantages of the educational application from their own experience. The process was questioned from the analysis in the face of overcoming difficulties and improving performance.)

- Overcoming difficulties. The organization and planning of the TFG is improved, the understanding and assimilation of content is improved, group relationships are improved

- Performance improvement. Greater work efficiency is achieved an exchange of information is very useful. Collaboration and work networks are created among students.

\section{CONCLUSION}

In general, the results indicate that the majority of the students of this experience favorably appreciate the $\mathrm{CL}$ and the advice and tutoring of the teachers as innovation in the improvement of the teachinglearning processes, with which the feeling disappears of insecurity and initial ignorance.

Collection of data is still pending of the qualifications of the September call, where we can analyze a more representative sample, but it is concluded among all the teaching staff the increase in the quality of the documents and the exhibition and defense made by the students.

The research paper exposes a new methodology, which highlights the improvement of the quality of the PFG, the improvement in the perception of the students when facing the PFG, improvement in the communication of the student with the teacher, improvement in the final evaluation of the PFG This methodology is feasible to implement in other Polytechnic Engineering Schools.

This Teaching Innovation Project is a beginning of an exciting project in which all participating teachers have collaborated in the most active way and always willing to propose proposals for improvement. It is clear that both the students and teachers create the work environment has led to improved satisfaction in both groups. To all these local improvements in the university field is added the integration with the social and business fabric by bringing these entities closer to the University.

\section{REFERENCES}

[1] Rekalde, I. (2011). ¿Cómo afrontar el trabajo fin de grado?: Un problema o una oportunidad para culminar con el desarrollo de las competencias. Revista Complutense de Educación, 22(2), 179193.

[2] M. Barbancho Pérez, A.M., Ortiz García, A., Tardón García, L.J., Peinado Domínguez, A. and Contreras, F.J. and Munilla Fajardo, Evaluación del Pensamiento Crítico y la Participación Activa de Los Estudiantes de La E.T.S.I. de Telecomunicación: I Jornadas Teleco Opina (C-252). VII Foro sobre Evaluación de la Calidad de la Investigación y de la Educación Superior: Libro de capítulos ISBN: 978-84-693-5316-5., 2013.

[3] Freire, M.P.; Díaz, R.; Martínez, F.; Maside, J.M.; Río, M.L. del y Vázquez, E. (2015). Valoración del proceso de enseñanza-aprendizaje en el Trabajo Fin de Grado. REDU: Revista de Docencia Universitaria, 13(2), 323-344.

[4] Martínez, P.; Pérez, J. y Martínez, M. (2014). Una (re)visión de la tutoría universitaria: La percepción de estudiantes y tutores de estudios de Grado. Revista de Docencia Universitaria, 12(1), 269-305. 
[5] Gómez, M.E.; Serrano, R. y Huertas, C.A. (2015). Los Trabajos Fin de Grado (TFG) del área de Educación en el sistema universitario español. En La educación Sí importa en el siglo xxi (pp. 161172). Madrid: Síntesis.

[6] T. Plomaritis, M. Puig, I. Laiz, and J. J. Muñoz-Perez, "Development of tutorials to promote selfdirected programming learning: application to postgraduate studies," Proc. EDULEARN17 Conf. 3rd-5th July 2017, Barcelona, Spain, 3120-3126, 2017.

[7] Salinas, B. y Cotillas, C. (2007). La evaluación de los estudiantes en la Educación Superior: Apuntes de buenas prácticas. Valencia: Servei de Formació Permanent. Universitat de València.

[8] Amor, M.I. (2012). La Orientación y la Tutoría Universitaria como elementos para la calidad y la innovación en la Educación Superior: Modelo de Acción Tutorial. Córdoba: UCO. Tesis doctoral. Recuperado el 10 de septiembre de 2015, de . 388 Educar 2018, vol. 54/2 M. E. Gómez; R. Serrano; M. I. Amor; C. A. Huertas

[9] M. Rubia and J. M. Marbán, "El Papel de las Nuevas Tecnologías en el Desarrollo de Proyectos Piloto de Innovación Docente," Revista Latinoamericana de Tecnología Educativa, 5 (2), 301-308., 2006.

[10] J. Gandia and M. Montagud, "Innovative teaching methods and students' academic performance: An empirical study on cost accounting education," Rev. Esp. Financ. Y Contab. J. Financ. Account. Vol. 40 Número 152 Páginas 677-698, 2011.

[11] M. Navarro-Pons, J. J. Muñoz-Pérez, G. Anfuso, J. Román-Sierra, and L. Moreno, "Success on increasing number of students that pass the coastal engineering subject," Proc. EDULEARN14 Conf. 7th-9th July 2016, Barcelona, Spain, 4443-4448, 2014.

[12] P. López-García, M. Navarro-Pons, J. J. Muñoz-Pérez, and G. Anfuso-Melfi, "Audiovisual resources as a useful tool to improve the teaching of Coastal Engineering (Marine Science BSc degree)," Proc. EDULEARN14 Conf. 7th-9th July 2016, Barcelona, Spain, 6117- 6124, 2014.

[13] Neves, M. G., Fontul, S., Miguez, M., Solari, S., Pedocci, F., Teixeira, L., \& Muñoz-Perez, J. J. (2015), "Methodologies for teaching an engineering subject in different countries: comparison and results," INTED2015 Proc., 1339-1346, 2015.

[14] Goikoetxea, E. y Pascual, G. (2002). Aprendizaje cooperativo: Bases teóricas y hallazgos empíricos que explican su eficacia. Educación XXI, 5, 227-247.

[15] Topping, K.J. (2005). Trends in peer learning. Educational Psychology, 25(6), 631-645. 